\title{
Comparative Analysis of Different Image Segmentation Techniques
}

\author{
Subodh Meshram ${ }^{1}$, C.N. Bhoyar ${ }^{2}$ \\ ${ }^{1}$ M. Tech Student, Department of Electronics Engineering, \\ Priyadarshini College of Engineering, Nagpur, Maharashtra, India, 440019 \\ ${ }^{2}$ Assistant Professor, Department of Electronics Engineering, \\ Priyadarshini College of Engineering, Nagpur, Maharashtra, India, 440019
}

\begin{abstract}
Image segmentation is vital in understanding and analyzing objects within images. An image may contain over one object and to segment, the image with object features to extract meaningful objects is challenging to the researchers within the field. the method involves in dividing indistinct images into meaningful and useful ones by segmenting them and subsequently evaluating them supported color density. This process is employed within the medical, cultural, industrial fields, and among others. There are many functions utilized in image segmentation, including edge and threshold functions. This paper will compare different sort of image segmentation techniques and can suggest an improved method.
\end{abstract}

Keywords- Image segmentation.

\section{I-INTRODUCTION}

F or Detecting objects in images, we have to understand image segmentation. We have to partition or divide the image into various parts called segments. A collection or set of different pixels is called an image. We can make a group together the pixels so that pixels having similar attributes using image segmentation. Image segmentation works like firstly divide the image into segments then we can use the important segments for processing the image. Image segmentation is technique of division and partition on an image into regions. In that region contains objects, parts of objects or group of objects which appears in the image. There are different types of image segmentation techniques like edge based, pixel based, region based, and model based which partition the image into several parts based on certain image features like color, pixel intensity value, texture, etc. Object detection builds a rough box for each group in the image, it gives nothing about the shape of the objects. We need more information to get our purposes.

Image segmentation methods give a more understanding of the objects in the images, sometimes images are corrupted due to external noise, in that area we have to put down the computational complexity, signal-to-noise ratio, and improve image quality and performance analysis also. The segmentation method is used to identify important regions in medical images, it is a unique technique for partitioning an image into meaningful sub-regions or object with the same attribute [1].

In the medical field, Image segmentation helps in Intrasurgery navigation, Locate tumors and other pathologies, a study of anatomical structure, Measure tissue volumes, Diagnosis, Surgery planning, Virtual 


\section{International Journal of Innovations in Engineering and Science, www.ijies.net}

surgery simulation, and Intra-surgery navigation. Different types of segmentation have been already proposed, Unfortunately, segmentation using traditional low-level image processing techniques, such as thresholding, histogram, region growing, and other classical operations requires a considerable amount of interactive guidance to attain satisfactory results [4]. In the industrial field, We can say that image segmentation plays a very crucial role. it helps in machine vision, object detection, recognition tasks, traffic control systems, video surveillance, and video object cosegmentation and action localization. Industrialists save their billions due to just using Image segmentation.

\section{II-NEED OF IMAGE SEGMENTATION}

As per WHO, nearly 10 million deaths are count because of cancer in 2020. It is important to detect cancer at an early stage, it directly impacts on the cancer mortality rate. With the help of image segmentation, we can save lives. Segmentation is a crucial stage of the image recognition system because it extracts the objects of our interest, for further processing like description or recognition. Segmentation of a picture is in practice for the classification of an image pixel. Segmentation techniques are wont to isolate the specified object from the image so as to perform analysis of the thing. for instance, a tumor, cancer, or a block within the blood flow is often easily isolated from its background with the assistance of an image segmentation technique. The segmentation of color images is more puzzled as each pixel within the color images is vector-valued.

\section{III-COMPARATIVE ANALYSIS AND DISCUSSION OF IMAGE SEGMENTATION METHODS}

Reem Alzu'bi et al. (2017) have proposed a new approach using K-means with Snake optimization method and Normalized Cut algorithm for betterments which is named as Optimized K-means for image segmentation. He studied Different image segmentation methods for medical image segmentation by various researches have been presented in this paper. It summarizes the divers reviews on image segmentation methods as well as techniques and appraised the performance against various database. He finally concluded that the traditional $\mathrm{k}$-means is not appropriate for segmenting the medical images and $\mathrm{K}$-means gives the best results for image segmentation with smaller number of $\mathrm{K}$ - values.
Pamarthy Chenna Rao et al. (2013) have proposed the area of image segmentation in content-based image retrieval. He referred to different segmentation techniques so that problem of segmentation can be solved. He suggested some future scope in the resolution of retrieval of images from content based images. He suggested to keep the provision of threshold values to be put by the users on the segmentation based on color, texture shape or spatial locations so as to enable them to control the accuracy of segmentation they desire in the output generated [2].

Shreya K Chari et al. (2017) have proposed that Renyi's entropy, Maximum entropy sum, and Tsallis entropy were found to be better than the Otsu's method for segmentation of given image, also the parametric measures offer a better solution for multimodal images which means when plotted on histogram one observes multiple peaks (maxima). In image segmentation, homogeneous pixel elements are identified in a given image then we can used for full object identification or clarification tasks. He has used entropy-based methods for improving the segmentation process by identifying threshold segmentation. Because of parametric entropy, Segmentation flexible to probe the pixel landscape in a better manner and this is an advantage.

Chen Wei-bin et al. (2010) have proposed a new method for improving the robustness of watershed algorithm based on mathematical morphology and applied to cellular image segmentation. His experimental results indicate that watershed technique can be significantly attenuated, and regions of interest are effectively reduced with that approach. Compared with other tradition methods, requires fewer computations and simpler parameters and can more efficiently reduce the over segmentation of the watershed algorithm [4].

Y. Ben Fadhel et al. (2016) have approaches two segmentation methods, first one is region-based segmentation detects homogeneities and the common features by using the active contour model (chan_vese) and the thresholding techniques. The second is edgebased segmentation, it seeks the existence of a transition between two related regions by using some methods like (Sobel, Canny and Perwitt). To improve the active contour model (chan_vese) segmentation result they applied a simple threshold succeed by the chan-vese model (combination of two techniques). 


\section{International Journal of Innovations in Engineering and Science, www.ijies.net}

Samandeep Kaur et al. (2016) have proposed various image segmentation techniques. and Result of image segmentation is depends on various factors like texture, pixel colour, intensity, similarity of images, image content and problem domain, and concluded that no one is perfect method for image segmentation. From the study it is clear that no single method is sufficient for every image type and not all methods are suitable for a particular image type. Due to the need of image segmentation in many applications, it has a challenging future [8].

PENGSHUAI YIN et al. (2016) proposed a multiscale network with guided filter modules for vessel segmentation, optic disc, and cup segmentation. A fundamental problem for biomedical image analysis is segmentation of 2D images. They introduced a deep guidance network to segment the biomedical image. His proposed network consists of a guided image filter module to restore the structure information through the guidance image. The network incorporates a guided image filter module to introduce more edge information from the guidance image to the neural network and restores the spatial information loss caused by the downsample operation. The extensive experiments on vessel segmentation and optic disc, and cup segmentation tasks verify the effectivenessof method [9].

Martin Rajchl et al. (2014) proposed a novel multiregion image segmentation approach to extract myocardial connective tissue from 3-D whole-heart cardiac late-enhancement resonance images in an interactive manner. Auther proposed a partially-ordered Potts (POP) model to multi-region segmentation to properly encode the recognized as spatial consistency of cardiac regions. They demonstrated that, the HMF-based algorithm is performed good as compare to methods which commonly found in the literature in terms of accuracy.

Awf Abdulrahman et al. (2020) is reviewed that image segmentation algorithms is transformed opaque images into meaningful ones through which vital information can be extracted. They used four types of images like Binary Images, Grayscale Images, RGB Images, and Indexed Images for observation which method is best for the segmentation. After observing Threshold-based segmentation, Edge-based segmentation, Watershed segmentation, Region-based segmentation this method they concluded that Region-based segmentation is comparatively good.
Tiechao Jiang et al. (2018) designed level set segmentation method based on CV model for segment the calcification of the vascular in medical images. CV model segmentation algorithm is precise for detecting vascular calcification. It is convenient for further measurement of the calcification, that can provide effective evidence for clinical diagnosis. With the help of vascular calcification segmentation process, they achieved image segmentation pretreatment, completed the $\mathrm{CV}$ model level set segmentation algorithm and using mathematical morphology to process the segmentation image.

Juin-Der Lee et al. (2009) proposed a segmentation method for brain MR images using a distribution transformation approach which is designed to fit nonGaussian tissue intensity distributions. Different Automatic segmentation methods proposed by Juin. In brain anatomical structures partition of images into gray matter (GM), white matter (WM), and cerebrospinal fluid (CSF) is an important. Studied results suggested that the proposed segmentation method yielded higher similarity measures for both gray matter and white matter as compared with those based on the traditional segmentation using the Gaussian mixtures approach [13].

Ravi Boda et al. (2016) proposed the image segmentation techniques namely Active Contour Method (ACM), Gray threshold Mechanism (GTM), Sobel Gradient Method (SGM) and Watershed Transform (WST). Above four segmentation methods are applied to medical Magnetic Resonance Imaging (MRI) images of Brain, Knee joints, Cardiac images, and Ultrasound. Ravi et al. used MRI images of sizes 128X128, 256X256, 512X512, and 1024X1024. The performance measure parameters like Peak Signal-to-Noise Ratio, Mean Square Error, time and entropy are calculated and compared for all image sizes. On the basis on implementation on MATLAB 2014a software, WST has better time response and SGM has better Entropy.

Min Chen et al. (2011) presented an automatic segmentation method for the spinal cord using a novel combination of deformable atlas based registration and topology preserving classification to address the challenges inherent to MR images of the spinal cord[15]. The automatic results from Atlas Registration, Topology Preserving Segmentation, and 2nd manual rater method were compared with the manual segmentations by calculating their Dice overlap. Min Chen's results 
International Journal of Innovations in Engineering and Science, www.ijies.net

showed a high level of accuracy compared to segmentations performed by manual raters.

Ionut Schiopu et al.(2017) proposed an image segmentation method for lossless compression of plenoptic images. Ionut Schiopu et al. The plenoptic cameras are using widely due to the advances in microlens array production, and reduced costs of hardware, which extended the range of applications. The plenoptic image contains the angular and spatial information needed to generate the 3D scene. They designed a set of new prediction contexts using a gradient-based edge detector and proposed a new segmentation algorithm for the already encoded reference image, which offers better contexts for CMS's entropy coder for encoding the current image. They introduced a preliminary segmentation algorithm based on scaled difference, and modifies the Quantum Cut algorithm to generate a preliminary segmentation for coding, and proposed a new strategy for views processing order.

Table I. Comparison Of Medical Image Segmentation By Various Researchers

\begin{tabular}{|c|c|c|c|}
\hline \multicolumn{4}{|c|}{ Comparison Of Medical Image Segmentation } \\
\hline Researcher & $\begin{array}{l}\text { Medical } \\
\text { image used } \\
\text { for research }\end{array}$ & $\begin{array}{l}\text { Better } \\
\text { method } \\
\text { from the } \\
\text { research }\end{array}$ & $\begin{array}{l}\text { Image } \\
\text { segmentati } \\
\text { on methods } \\
\text { and } \\
\text { Techniques } \\
\text { used for } \\
\text { comparison }\end{array}$ \\
\hline $\begin{array}{l}\text { Reem } \\
\text { alzu'bi }\end{array}$ & Mri images & $\begin{array}{l}\text { K-means } \\
\text { with snake } \\
\text { optimizati } \\
\text { on method } \\
\text { and } \\
\text { normalize } \\
\text { d cut } \\
\text { algorithm }\end{array}$ & $\begin{array}{l}\text { KNN, } \\
\text { SVM, k- } \\
\text { means, } \\
\text { fuzzy c- } \\
\text { means, } \\
\text { optimized } \\
\text { k-means, } \\
\text { snake } \\
\text { optimizatio } \\
\text { n method } \\
\text { and } \\
\text { normalized } \\
\text { cut } \\
\text { algorithm }\end{array}$ \\
\hline $\begin{array}{l}\text { Pamarthy.ch } \\
\text { enna rao }\end{array}$ & $\begin{array}{l}\text { Content- } \\
\text { based image }\end{array}$ & $\begin{array}{l}\text { Region } \\
\text { based } \\
\text { segmentati } \\
\text { on }\end{array}$ & $\begin{array}{l}\text { Threshold } \\
\text { techniques, } \\
\text { edge-based } \\
\text { methods, } \\
\text { region- } \\
\text { based }\end{array}$ \\
\hline
\end{tabular}

\begin{tabular}{|c|c|c|c|}
\hline & & & $\begin{array}{l}\text { techniques, } \\
\text { and } \\
\text { connectivit } \\
\text { y- } \\
\text { preserving } \\
\text { relaxation } \\
\text { methods }\end{array}$ \\
\hline $\begin{array}{ll}\begin{array}{l}\text { Shreya } \\
\text { chari }\end{array} & \mathrm{k} \\
\text { char }\end{array}$ & $\begin{array}{l}\text { Digital } \\
\text { image }\end{array}$ & $\begin{array}{l}\text { Otsu's } \\
\text { method }\end{array}$ & $\begin{array}{l}\text { Maximum } \\
\text { entropy } \\
\text { sum, tsallis } \\
\text { entropy } \\
\text { and renyi's } \\
\text { entropy }\end{array}$ \\
\hline $\begin{array}{l}\text { Chen wei- } \\
\text { bin }\end{array}$ & $\begin{array}{l}\text { Cellular } \\
\text { image }\end{array}$ & $\begin{array}{l}\text { A new } \\
\text { watershed } \\
\text { algorithm }\end{array}$ & $\begin{array}{l}\text { Cellular } \\
\text { image } \\
\text { segmentati } \\
\text { on }\end{array}$ \\
\hline $\begin{array}{ll}\text { Y. } & \text { Ben } \\
\text { fadhel } & \end{array}$ & $\begin{array}{l}\text { Ventricular } \\
\text { ejection } \\
\text { fraction } \\
\text { images }\end{array}$ & $\begin{array}{l}\text { Region- } \\
\text { based } \\
\text { segmentati } \\
\text { on as the } \\
\text { chan-vese } \\
\text { model }\end{array}$ & $\begin{array}{l}\text { Region- } \\
\text { based } \\
\text { segmentati } \\
\text { on as gary } \\
\text { level } \\
\text { thresholdin } \\
\text { g and edge- } \\
\text { based } \\
\text { segmentati } \\
\text { on as } \\
\text { derivate } \\
\text { methods }\end{array}$ \\
\hline $\begin{array}{l}\text { Samandeep } \\
\text { kaur }\end{array}$ & $\begin{array}{l}\text { Digital } \\
\text { image }\end{array}$ & $\begin{array}{l}\text { Region } \\
\text { based } \\
\text { segmentati } \\
\text { on }\end{array}$ & $\begin{array}{l}\text { Pixel-based } \\
\text { segmentati } \\
\text { on, edge- } \\
\text { based } \\
\text { segmentati } \\
\text { on, model- } \\
\text { based } \\
\text { segmentati } \\
\text { on, region- } \\
\text { based } \\
\text { segmentati } \\
\text { on }\end{array}$ \\
\hline $\begin{array}{l}\text { Pengshuai } \\
\text { yin }\end{array}$ & $\begin{array}{l}\text { Biomedical } \\
\text { image }\end{array}$ & $\begin{array}{l}\text { Vessel } \\
\text { segmentati } \\
\text { on, optic } \\
\text { disc and } \\
\text { cup } \\
\text { segmentati } \\
\text { on }\end{array}$ & $\begin{array}{l}\text { U-net, driu, } \\
\text { ce-net, } \\
\text { laddernet, } \\
\text { vesselnet }\end{array}$ \\
\hline Martin rajchl & $\begin{array}{ll}\text { Cardiac } & \mathrm{mr} \\
\text { images } & \end{array}$ & $\begin{array}{l}\text { Multi- } \\
\text { region } \\
\text { segmentati } \\
\text { on method }\end{array}$ & $\begin{array}{l}\text { Full-width- } \\
\text { at-half- } \\
\text { maximum } \\
\text { and signal- } \\
\text { threshold } \\
\text { to } \\
\text { reference- } \\
\text { mean } \\
\text { methods }\end{array}$ \\
\hline
\end{tabular}




\section{International Journal of Innovations in Engineering and Science, www.ijies.net}

\begin{tabular}{|c|c|c|c|}
\hline $\begin{array}{l}\text { Awf } \\
\text { abdulrahman }\end{array}$ & $\begin{array}{l}\text { Binary } \\
\text { images, gray } \\
\text { scale } \\
\text { images, rgb } \\
\text { images, } \\
\text { indexed } \\
\text { images }\end{array}$ & $\begin{array}{l}\text { Region- } \\
\text { based } \\
\text { segmentati } \\
\text { on }\end{array}$ & $\begin{array}{l}\text { Threshold- } \\
\text { based } \\
\text { segmentati } \\
\text { on, edge- } \\
\text { based } \\
\text { segmentati } \\
\text { on, } \\
\text { watershed } \\
\text { segmentati } \\
\text { on, region- } \\
\text { based } \\
\text { segmentati } \\
\text { on }\end{array}$ \\
\hline $\begin{array}{l}\text { Tiechao } \\
\text { jiang }\end{array}$ & $\begin{array}{l}\text { Vascular } \\
\text { medical } \\
\text { images }\end{array}$ & $\begin{array}{l}\mathrm{Cv} \text { model } \\
\text { segmentati } \\
\text { on } \\
\text { algorithm }\end{array}$ & $\begin{array}{l}\text { Nonlinear } \\
\text { spatial } \\
\text { filtering } \\
\text { method }\end{array}$ \\
\hline Juin-der lee & Mri images & $\begin{array}{l}\text { Power } \\
\text { transforma } \\
\text { tion } \\
\text { approach }\end{array}$ & $\begin{array}{l}\text { Gaussian } \\
\text { mixtures, } \\
\text { gaussian } \\
\text { mrf, power } \\
\text { transformat } \\
\text { ion - mrf, } \\
\text { spm5, } \\
\text { mpm-map }\end{array}$ \\
\hline Ravi boda & Mri images & $\begin{array}{l}\text { Watershed } \\
\text { transform } \\
\text { (wst) }\end{array}$ & $\begin{array}{l}\text { Active } \\
\text { contour } \\
\text { method } \\
\text { (acm), gray } \\
\text { threshold } \\
\text { mechanism } \\
\text { (gtm), } \\
\text { sobel } \\
\text { gradient } \\
\text { method } \\
\text { (sgm) and } \\
\text { watershed } \\
\text { transform } \\
\text { (wst). }\end{array}$ \\
\hline Min chen & Mri images & $\begin{array}{l}\text { Automatic } \\
\text { segmentati } \\
\text { on method }\end{array}$ & $\begin{array}{l}\text { Manual } \\
\text { segmentati } \\
\text { on }\end{array}$ \\
\hline $\begin{array}{l}\text { Ionut } \\
\text { schiopu }\end{array}$ & $\begin{array}{l}\text { plenoptic } \\
\text { images }\end{array}$ & $\begin{array}{l}\text { Preliminar } \\
\text { y } \\
\text { segmentati } \\
\text { on either } \\
\text { by scaling } \\
\text { the } \\
\text { intensity } \\
\text { differences } \\
\text { or by } \\
\text { using a } \\
\text { quantum } \\
\text { cut based } \\
\text { algorithm }\end{array}$ & $\begin{array}{l}\text { Cms, aps, } \\
\text { scaled } \\
\text { difference } \\
\text { segmentati } \\
\text { on, } \\
\text { quantum } \\
\text { cut based } \\
\text { segmentati } \\
\text { on for } \\
\text { coding }\end{array}$ \\
\hline
\end{tabular}

\section{IV-CONCLUSION}

This paper summarizes the different reviews on image segmentation methods and techniques. I used different dataset for evaluation of the performance. This review paper helps researchers to select appropriate image segmentation method. After studied, I concluded that every method and technique has pros and cons so it's depend on requirement which method we have to used. Future work can be extended by carrying with different Image segmentation architectures like U-Net, FastFCN, Gated-SCNN, DeepLab, and Mask R-CNN architecture..

\section{REFERENCES}

[1] Reem Alzu'bi, Dr. A. ANUSHYA, Ebtisam Hamed, Eng.Abdelnour AlSha'ar, B.S Angela Vincy , "Medical Image Segmentation via Optimized K-Means" in International Conference on Current Trends in Computer, Electrical, Electronics and Communication (ICCTCEEC-2017), pp. 959 - 962

[2] Pamarthy.Chenna Rao, "Analysis of Image Segmentation Techniques and Searching for Future Scope of Research" in International Journal of Engineering Research \& Technology (IJERT) Vol. 2 Issue 10, October - 2013, pp. 147 - 150

[3] Shreya K Chari, Akarshit Gupta, Prabhav Gupta, Jitendra Mohan, "Threshold Selection in Image Segmentation Using Parametric Entropy Measures" in 2017 Fourth International Conference on Image Information Processing (ICIIP), pp. 273 - 277

[4] Chen Wei-bin, Zhang Xin, "A New Watershed Algorithm for Cellular Image Segmentation Based on Mathematical Morphology" in 2010 International Conference on Machine Vision and Human-machine Interface, pp. $653-656$

[5] Robert Manzke, Carsten Meyer, Olivier Ecabert, Jochen Peters, Niels J. Noordhoek, Aravinda Thiagalingam, Vivek Y. Reddy, Raymond C Chan, and Jürgen Wees, “Automatic Segmentation of Rotational $X$-Ray Images for Anatomic Intra-Procedural Surface Generation in Atrial Fibrillation Ablation Procedures" in IEEE TRANSACTIONS ON MEDICAL IMAGING, VOL. 29, NO. 2, FEBRUARY 2010, pp. 260 - 272

[6] Anshul Malik, R.K.Sharma, "DETECTION OF HEART CONDITIONS USING HRV PROCESSOR IN MATLAB SIMULINK" in International Conference on Trends in Electronics and Informatics ICEI 2017, pp. $861-864$

[7] Y. Ben Fadhel, S. Ktata and T. Kraiem, "Cardiac Scintigraphic Images Segmentation Techniques" in 2nd International Conference on Advanced Technologies 
for Signal and Image Processing - ATSIP'2016 March 21-24, 2016, Monastir, Tunisia, pp. 364 -369

[8] Samandeep Kaur, "Study of Various Image Segmentation Techniques" in International Journal of Innovative Research in Computer and Communication Engineering, pp. 19657 - 19661

[9] PENGSHUAI YIN, RUI YUAN, YIMING CHENG AND QINGYAO WU, "Deep Guidance Network for Biomedical Image Segmentation" in IEEE Access 2020, VOLUME 4, 2016, pp. pp $1-11$

[10] Martin Rajchl, Jing Yuan, James A. White, Eranga Ukwatta, John Stirrat, Cyrus M. S. Nambakhsh,Feng P. Li, and Terry M. Peters, Fellow, IEEE, "Interactive Hierarchical-Flow Segmentation of ScarTissue From Late-Enhancement Cardiac MR Images" in IEEE TRANSACTIONS ON MEDICAL IMAGING, VOL. 33, NO. 1, JANUARY 2014, pp. 159 - 172

[11] Awf Abdulrahman, Serkan Varol, "A Review of Image Segmentation Using MATLAB Environment" in Authorized licensed use limited to: University of Exeter. Downloaded on June 21,2020 at 02:18:21 UTC from IEEE Xplore

[12] Tiechao Jiang, Xiaoqiang Ji, "The Vascular Calcification Image Segmentation Based on CV Model" in 2018 11th International Congress on Image and Signal Processing, BioMedical Engineering and Informatics (CISP-BMEI 2018

[13] Juin-Der Lee, Hong-Ren Su, Philip E. Cheng*, Michelle Liou, John A. D. Aston, Arthur C. Tsai, and Cheng-Yu Chen, "MR Image Segmentation Using a Power Transformation Approach" in IEEE TRANSACTIONS ON MEDICAL IMAGING, VOL. 28, NO. 6, JUNE 2009, pp. $894-905$

[14] Ravi Boda, Sudheer Kumar Yezerla, B. Rajendra Naik, "Performance Analysis of Image Segmentation methods for Noisy MRI images" in International Conference on Communication and Signal Processing, April 6-8, 2016, India, pp. $942-946$

[15] Min Chen, Aaron Carass, Jennifer Cuzzocreo, PierreLouis Bazin, Daniel S. Reich and Jerry L. Prince, "TOPOLOGY PRESERVING AUTOMATIC SEGMENTATION OF THE SPINAL CORD IN MAGNETIC RESONANCE IMAGES" in 2011 IEEE, pp. $1737-1740$

[16] Ionut Schiopu, Moncef Gabbouj, Alexandros Iosifidis, Bing Zeng, and Shuaicheng Liu, "Subaperture Image Segmentation for Lossless Compression" in 978-15386-1842-4/17/\$31.00 @2017 IEEE 